Canadian Journal of Family and Youth, 5(1), 2013, pp 65-89

ISSN 1718-9748 ( ) University of Alberta

http://ejournals.library.ualberta.ca/index/php/cjfy

\title{
Daughters of Single Fathers: Working as a Team
}

Heather Currie and Steve Sider

\begin{abstract}
In this paper, we consider the perspectives of daughters of single fathers as they reflect on their experiences and relationships with their fathers. The paper provides an opportunity to consider an under-represented group in the literature on single parent families. Three themes emerge from the qualitative research design: parental expectations and involvement, household tasks, and family relationships. We consider these themes in light of the work done by BronteTinkew et al (2010) and Risman (1986) regarding the involvement and support of single fathers in the lives of their children. We conclude by providing suggestions for teachers and other professionals regarding single fathers and their daughters.
\end{abstract}

\section{Introduction}

One particular family type that we have seen greatly increase in Canada is the single father family. In this type of family, the children primarily reside with the father and it is the father who is responsible for child rearing and providing. Over the past twenty years, single fathers in Canada have been greatly outnumbered by single mothers. In 2006, the majority

Heather Currie is an Early Childhood Educator at a childcare centre in Guelph, Canada. She is currently working towards her Master of Education degree at Wilfrid Laurier University, Waterloo, Canada. She was raised by a single father, and consequently is interested in the experiences of single fathers and their children. Steve Sider is an Assistant Professor in the Faculty of Education at Wilfrid Laurier University, Waterloo, Canada. His Ph.D., from Western University, focused on the linguistic experiences of immigrant children in rural Canada. Previously he was a secondary school administrator who was engaged in global citizenship projects in Canada, Thailand, and India. For the past eight years, he has been working with Haitian school principals in leadership capacity-building. 
(80.1\%) of the $1,414,100$ lone-parent families were comprised of women and their children (Statistics Canada, 2006). However, between 2001 and 2006 there was a 14.6\% increase in single father families in Canada, indicating rapid growth among this family type (Statistics Canada, 2006). Although single father families are on the rise, they are under-represented in educational research.

All too often single fathers are put under the umbrella term, single parents. This is problematic since single fathers represent a unique group, with experiences and challenges that are different from their single mother counterparts. As well, the children of these single fathers, and of particular interest to this paper, their daughters, represent a group that has seen only limited research. In order for community agencies and professionals such as teachers, judges, social workers, and doctors to be successful in providing services for single father families, it is critical that they first understand them. The purpose of this paper is to describe the experiences of three daughters of single fathers in an urban community. A case study research method approach was used to look at the attributes, challenges, and needs facing this unique group of females. Data was gathered through in-depth interviews of three female participants, between the ages of 15 and 23, whose fathers had been the sole caregiver for a minimum of two years. The findings from the research study are presented according to three overarching themes: parental expectations and involvement, household tasks, and family relationships.

\section{Literature}

Within the research on single parent families, there has been more extensive attention given to mothers who are single parents than to fathers. This body of research has a broad range from studies which examine the experiences of single mothers in rural areas compared with 
urban communities (Brown \& Lichter, 2009) to a meta-analysis of studies regarding poverty amongst single mothers (Broussard, 2010). Research which has examined issues of gender and income in single parent families has not indicated that the gender of the parent significantly impacts the psycho-social development of the child. For example, in a meta-analysis of studies related to single parent families, Biblarz and Stacey (2010) determined that the gender of the parent has little to do with the child's psychological adjustment and social success. They reported that single-fathers enjoy, in general, some significant advantages over single mothers including higher income levels and more stable employment (Biblarz \& Stacey, 2010). Thus, the experiences of single parent families may be as much about income and class as it is about gender.

Research in Canada in the field of single fathers and their children has been limited and began in Canada in the 1960's (Risman, 1986). During this time studies mainly examined whether or not fathers were capable of lone parenting and attention was given to the challenges they faced in attempting to prove themselves within society as suitable caregivers. More recent research has looked at the challenges facing single fathers; in particular, the research focus is often on the father's socioeconomic status and its impact on parenting (Emmers-Sommer, Rhea, Triplett \& O’Neil, 2003).

There have been numerous studies which have focused on various development issues of children who live with single parents. For example, Weiss (2010) proposes that single parent families share management responsibilities between parent and children and that, as a result, the children tend to mature more quickly. Other studies have examined issues such as the response of children to various forms of parental separation (Amato \& Kane, 2011). However, there has 
been limited attention provided in the research on the lived experiences of single fathers or their daughters.

Three studies are worth noting which have examined single father families with special attention to the children within these families. First, Bronte-Tinkew, Scott, and Lilja (2010) used data from the National Longitudinal Survey of Youth to gain an understanding of 3,977 youths who lived with their father as their primary caregiver. Bronte-Tinkew et al (2010) focused on the relationship between the father and adolescent and how this influenced the children as they entered young adulthood. They discovered that single father families have unique characteristics, such as parenting style and involvement in their children's lives, differentiating them from other family types. Typically, single fathers seem to employ a permissive parenting style, characterized by responsiveness, acceptance, and affirmation (Bronte-Tinkew et al, 2010).

Lee and Kushner (2008) used national survey data from the United States to investigate whether adolescents living with parents of their same gender fare better on academic achievement than their peers living with opposite-gender parents. In past research, same-gender advantage hypothesis has attempted to support the notion that same-gender parents are better equipped to deal with the developmental stages of their same-gender child (Lee \& Kushner, 2008). Results from the Lee and Kushner study indicated that females of single fathers actually fare better in academic tasks than all other counterparts.

A third study, by Greif (1985), examined the topic of children and housework in the single father family from a quantitative lens. A total of 1,136 fathers were given surveys regarding their experiences. Greif (1985) found that children in single father families were more likely to participate in housework than children living in two parent families. Typically, single 
fathers do not recruit female help from outside of the home; they either complete work themselves or in conjunction with their children (Risman, 1986).

The literature on single father families is limited in a number of ways. In the work by Greif (1985) and Emmers-Sommer et al (2003), the focus is primarily on the father's context and experience. Lee and Kushner's (2008) work was set in the United States, providing important insights but in a different socio-political context nonetheless. The work of Bronte-Tinkew, Scott, and Lilja (2010) is valuable due to its scope and focus on the Canadian context but without a specific focus on the lived experiences of daughters of single fathers. Other research has focused on the father's experience with raising children (Chang \& Deinard, 2010) and the impact which fathers have in helping shape their daughters' occupational choices (Hellerstein \& Morrill, 2011). Again, we see a focus in the literature on the experiences of the father with limited consideration for the perspectives of their daughters.

Since much of the literature which exists on single father families has focused on the experience of the father, we have a limited qualitative understanding of the perspectives, challenges, and needs which daughters of single fathers encounter. Further, daughters of single fathers are not often given a voice in the research. Most of what we know about children living with single fathers is derived from secondary sources such as parents and teachers (Supino, 2002). As a result, there has been a limited descriptive, qualitative examination of the lived experience of daughters of single fathers. It is for these reasons that we considered an exploratory study to examine the perspectives and insights of daughters of single fathers. This paper provides an important contribution to the research on single father families by considering the voices of the daughters in these families. 


\section{Methodology}

\section{Participants}

Based on the present gap in the literature around considering a daughter's perspective on being part of a single father family, we invited three females who had lived in single father families to participate in this exploratory case study. We chose a case study methodology because it provides an opportunity to consider the lived experience of a limited number of participants. We wanted to focus on a small group of participants so as to provide as rich and informative insight as possible. By narrowing our examination to three cases, we were provided with an opportunity to examine a variety of experiences more closely than if we had a larger sample size. As well, using a multiple case method allowed for consideration of different perspectives and is therefore more robust than a single case (Yin, 2003). Research considerations were in line with qualitative research practices: the reporting of qualitative study is descriptive, the methodology is emergent and flexible, and the selection of participants is usually nonrandom, purposeful, and small (Merriam, 1998).

We recognize that case study research is limited in its generalizability. However, we align our work with Stake's (2000) suggestion that the purpose of case research is not to represent a situation or phenomenon in its entirety, but to represent the case. As an exploratory study, we value that the descriptions and interpretations which develop from the data will help the participants and others arrive at "high quality understandings" (Stake, 1995, p. 88). As Wallen and Fraenkel (2001) suggest, "The outcome . . is not the generalization of results, but rather a deeper understanding of what goes on from the perspectives of the participants in the study" (p. 433). Stake (2000) suggests that although case studies are not usually generalizable, they can assist people in making naturalistic generalizations; people will make connections 
between the case studies and their own life experiences, so that "It is the reader of a qualitative study, not the researcher conducting the study, who determines the study's generalizability, if such seems appropriate” (Wallen \& Fraenkel, 2001, p. 435).

Participants in this study consisted of three females, ages 15, 21 and 23, all living in an urban community in central Canada. We purposefully sought mature female participants so that they may thoughtfully reflect on the experience of living in a single father family. A technique that assisted in identifying the key cases was snowballing or chain sampling (Isaac \& Michael, 1997). This method aims to identify key informants by asking such questions as "Who do you know that is the daughter of a single father?" By doing so, one informant leads to another, until significant cases are identified. All three female participants had lived or were currently living with their father as the primary caregiver for a minimum of two years. Two of the females lived with their father as a result of a parental separation and one of the females lost her mother due to illness at a young age (for an overview of the participants, see the Appendix).

\section{Data Collection}

The data used in this study was derived through in-depth interviews of participants, in addition to field notes. The interview format was semi-structured and the questions were openended. Probing questions were asked to expand and elaborate on the participants' responses. Yin (2003) suggests that, "One insight into asking good questions is to understand that research is about questions and not necessarily about answers" (p. 60). Using this method of open-ended questioning we hoped to facilitate a sharing of life experiences (Fontana \& Frey, 2000). We recognized that each participant had a unique story to tell. As a result, we allowed for significant opportunity for the participants to help direct the interviews. 
Several open-ended questions were developed prior to the interviews as prompts for gathering data but participants were encouraged to elaborate and direct the discussion in ways they felt comfortable. Thus, in keeping with qualitative research methods, opportunities for sharing and dialogue were encouraged (Fontana \& Frey, 2000). Participants were asked to answer questions based on their comfort level and life experience. All interviews took place in the participant's home or other venue in which the participant felt comfortable. The interviews were completed privately without fathers or other family members present. Interviews were recorded so data could later be transcribed and emerging themes identified. Following the interviews, in keeping with typical qualitative research methods, member checking occurred; participants were sent transcriptions in order to ensure that data recorded was accurate in representation.

Case studies provide opportunity to interpret and analyze data even as it is being collected (Stake, 1995). We saw this as valuable because we were able to regularly validate or clarify issues that were raised in the interviews or observations. Although we provided the participants with transcripts of interviews, we also frequently confirmed information with them as the study progressed. This dialogue allowed for new themes and ideas to be discovered and explored.

As the data was examined, we considered ways to accurately present the individual and the collective experiences of the participants. We examined the data for general content and then searched for consistency and meaning through the identification of themes and ideas. We used the constant comparative method of returning to the data repeatedly in order to develop the themes. Through this content analysis, we considered the surface content as well as the underlining meaning (Wallen \& Fraenkel, 2001). This approach provides opportunity for 
developing an understanding of the "why" associated with participants' responses. In the next section, we examine three themes which emerged from the case studies: parental expectations and involvement, household tasks, and family relationships. The themes are illustrated through the voices of Kate, Emily, and Dana (all names are pseudonyms for the participants).

\section{Results}

Parental Expectations and Involvement

All three participants described their father as firm or strict, but also fair. The three participants indicated that some rules for the home were obvious and non-negotiable; rules were set in place and expected to be followed and respected. Emily described her father as having expectations for certain aspects of their relationship but also being flexible. She stated, "There were just certain things and that was that and there was no way around that, no bending that and then there were other things that were, well whatever." Kate described her father as, "Strict, but strict in a way that sometimes it seemed unfair ... but when you look back on it, strict but fair."

As all three females got older they reported that their fathers were somewhat uncomfortable with them dating and with having boys in the house. For example, in Dana's house, boys were not permitted to come in the house and she stated that her father did not like her boyfriends because of the simple fact that they were dating his daughter. Emily shared a story about the time she mistakenly thought it would be acceptable to watch a movie with her boyfriend, in her bedroom, with the door closed. When her father found her he used a firm tone, expressing his anger over her decision, and demanded she come downstairs immediately. When Kate brought her first boyfriend home she said her father sat him down at the table and did the whole, "what are your intentions with my daughter thing." She described this as embarrassing, 
but seemingly expected because of her father's protective nature. Although all of the fathers were presented as strict, the participants still indicated a level of respect for their father and his role in the family.

Kate, Emily, and Dana all reported that school was of importance to their fathers and their fathers were involved in their overall educational experience. Further, all three indicated that their father would sit down with them and either help with homework, review tests, read agenda books, or help them strengthen their skills in a particular subject area. In Kate's experience, her dad printed off practice math sheets for her younger sister when she was struggling. However, she said that he never attended parent-teacher interviews because he thought they were "silly and ridiculous." Kate also shared that her father did not have to worry about her achievement level because of her identified giftedness.

Emily reported that on occasion her father would take her to the library for school projects if necessary. She shared that her father was not overly concerned with grades, but rather wanted to ensure that she was learning. She commented,

He wasn't a very pushy parent for marks and stuff, unless it was below a C. If it was below say $60 \%$ you were in trouble. But if it was $60 \%$ he'd actually sit with you and look at your test and say 'oh okay, this is good you passed' and whatever, 'but why did you screw up here, and what did you do here. Why didn't you get that?'

Similarly, Dana shared how her father wanted her to do well in school and make it a priority. He supported her in doing this by sitting down with her to help her with homework and ensuring that she did not have too much responsibility other than school. Dana reported that living with her father actually increased her grades. She attributed this to the stability that her father provided for her in addition to the great value he placed on education. 
In addition to being involved in the educational experiences of their child, all of the fathers were involved in the extracurricular activities that their child participated in. Kate's dad was always sure to be at important events in her life, including sports events. Dana, a music student, shared that her father heavily supported her passion for music, coming to all her concerts and even helping her fundraise for a high school trip.

Aside from educational and extracurricular involvement, fathers were somewhat involved in their daughter's personal life. Although all three participants indicated that they did not talk to their father about boys, they did report that their fathers were knowledgeable about their friends. Kate said that at one point her sister had a friend her father did not like. Kate's father expressed his concern about the friend and her sister was able to understand and respect the concern. Even in this situation, Kate's father expressed his concern about the negative influence of the girl but allowed Kate's sister to make the choice herself as to whether she would continue to hang out with her. This balance of being strict, but recognizing the daughter's independence and ability to make her own decision, was an important discussion point for the participants.

\section{Household Tasks}

When it came to responsibilities at home there were varied responses in terms of who was responsible for household chores. All three participants identified their fathers as very neat and clean. In all situations, expectations were set for a clean home. Dana admitted that she did as little as possible to contribute to the overall upkeep of the house. Her father did the cooking, cleaning, groceries, and laundry. Both Kate and Emily had to help out with basic chores like keeping their room clean and doing dishes. Emily said that as she got older it was expected that she would take on more responsibility in the home in the form of laundry and cleaning the 
bathroom. Emily also shared how in the absence of her mother her older sister took on the role of being a "mom" occasionally. In Kate's situation, she described herself as having a fair, but large amount of responsibility. She viewed this as more of something that simply kept the family running, rather than a frustration. She very much respected her role and contribution to the family. She noted that, "It's more like we were working together ... [but] for my friends it was just [a] chore [doing household work], whereas for me it was 'this is how we keep the house going." Kate was the only participant who was expected to cook meals and babysit her younger sister. When she was just 12 years old, her father would leave her for the night to cook dinner, watch her sister, and then put her to bed later.

While none of the participants indicated that assistance was recruited in the form of a cleaning service or nanny, all three did share that at one point or another, an aunt would provide support to the family. When Kate's parents first separated the family lived with her aunt, which, as a result, meant that Kate did not have many household responsibilities. In Emily's case, after her mother had passed away her aunt would come over to help out and ensure things were running smoothly, especially in the mornings. Emily stated, "My aunt would come over for a while and help us out; this was my mom's older sister. So, we had to get ourselves up and [she would help with] stuff like that." A supportive aunt was common to all three participants, although the level of their involvement varied for each person.

\section{Family Relationships}

The two words that participants used most often to describe their family relationship were trust and respect. Kate frequently used the word respect to describe her relationship with her dad and made it clear that this was a reciprocal feeling in her house. She indicated that she had to 
give her dad respect in order to get respect. Kate also used the word trusting to describe her relationship with her dad. She trusted the decisions he made and that the advice that he gave her was in her best interest. Dana also indicated that her relationship with her dad revolved around trust. She shared that although sometimes he had to make difficult decisions for the family, he was open and honest with her about why they had to be made. All three participants said that they currently have a close relationship with their father and that this relationship only seems to grow stronger with time. Dana indicated that, after she became a parent herself, she realized how much she relied on her dad and valued his opinion and advice.

As a young adult, Emily shared how her father still supported her and her sisters. When asked about whether or not she and her siblings still rely on her father Emily said, "Oh yeah, we all do, we all still rely on him. We will still be like 'Dad what do we do?', or 'Dad can you watch her [daughter]? I need a break." 'When Kate was asked about how she sees her relationship in the future with her father she indicated that she felt that as she got older they got closer. Kate stated, "I require him almost more now, just as I am getting out into the world. I think as I become more independent from the house I will still require him a lot just like the rock in my life. He's the rock."

When discussing overall family relations, Kate and Emily both shared how their experience living with a single father taught them specific values. Kate discussed the importance of sitting down together each night for dinner. Her father instilled this value in her and the idea that some families do not take the time to do this each night was surprising and almost appalling to her. Through this nightly routine, her family strengthened their overall connection to each other. Kate also talked about her dad's value of hard work and how it resulted in her developing 
a strong work ethic as well. Kate was expected to initially help at home without being given an allowance and when she got older she was expected to get a part-time job outside of the home.

In Emily's situation, her older sister stepped in to support the family in many ways after her mom passed away. Emily recognized that her sister did not have to stay home and help her family, however, she did and Emily learned from this. Emily stated, "That was kind of interesting considering she was in her early twenties and she could go if she wanted to, she didn't have to stay. She didn't have to do that, but she did it anyways. So that was what I found [that] you're a team, you work together. All for one and one for all, basically." When Emily talked about her mom's absence she said it was like missing a limb in a sense: When you lose your leg everything else on your body needs to work harder and more in sync for success. Without her mom, her family needed to work more as a team and consequently she described her family as stronger because of it.

Although all of the families had apparently strong connections and relationships, communication proved to be an area of difficulty for all three females. They all shared that, at times, they have had trouble communicating emotions to people. They each stated that they felt that they were "more private" than most people. Kate suggested that the difficulty she experienced when attempting to talk to other people about emotions or just "things" is because she would never talk to her dad about those things.

Interestingly, all three participants felt that not having a mother at home had made it difficult for them in some personal and relational areas. They referred to situations such as choosing clothes, dealing with make-up, and responding to some relationship issues which they felt they could not talk about with their fathers. With the female parental influence missing, Emily and Kate felt as though their fathers were less perceptive to their needs in some ways. For 
example, Kate shared how her sister seemed to be unaware of hygiene issues. Kate felt that if her mom had been present this may have been noticed. Emily shared how when she was in high school she struggled with eating healthily and lost a large amount of weight. Her father did not notice in the same manner that she felt her mom would have. Emily said, "She would have been like, 'What's going on?' I think it would have been different. I could have been like, 'Mom what's wrong, do I not look right?'” Eventually it was Emily's friends who noticed her unhealthy eating habits and supported her.

Both Kate and Emily reported feeling insecure about their family's financial situation, although neither of their fathers ever directly indicated that there was cause for concern. Emily recalled some specific experiences that led her to believe they had little money: Her older sister got a job and started contributing to household bills, she had to re-use a lot of school supplies, and she had to wear lots of hand-me-downs from her cousins. She indicated that whenever her older siblings asked for money her father simply replied with lines like, "No, do you think money grows on trees?" As a result Emily said she did worry about money: "So you know I started thinking about money more and that was really weird for someone who is 9 or 10 years old to be doing - 'I don't know if I can afford that."'

Kate also viewed specific experiences as indicators that money was tight. Although her father ensured there was ample opportunity for involvement in extracurricular activities, Kate still sensed that money was a problem. She said that when her family was looking for a new home, financial considerations were evident because everything was too expensive for them and they ultimately had to get a home that needed a lot of work. Further, she reported that things like eating lots of Hamburger Helper and reusing household supplies reaffirmed her feelings of being financially insecure. 
When the participants considered how living with a single father had influenced who they are today, the participants used words like independent, mature, and responsible. These descriptors may have been chosen as a result of the parenting expectations of their fathers, the types of household tasks they had to do, or due to their fathers' involvement in their lives. Certainly, as will be discussed further in the next section, the three participants felt that these characteristics were directly attributable to living in a single father family.

\section{Discussion}

The three participants indicated that, in some form, their father was strict, yet easygoing as a parent. Some rules were nonnegotiable, but in general, all of them shared that they were allowed to exercise control over many aspects of their life (friends, extracurricular activities, food choices). Bronte-Tinkew et al (2010) found that single fathers, typically, seem to employ a permissive parenting style, characterized by responsiveness, acceptance, and affirmation. They are willing to let their children explore and engage in activities independently, and are typically less controlling and less involved. Perhaps this could explain why participants in this study reported a sense of independence and maturity at a young age. Further, in terms of involvement, Bronte-Tinkew et al (2010) suggest that overall levels of involvement (communication and closeness) appeared to be lower among single fathers than any other group. This study found this to hold true around certain aspects of communication, but not all. For example, participants reported that they found it difficult to communicate with their father about emotions, personal issues, and boys, but conversations easily flowed around most day-to-day topics and issues. However, in no way did participants suggest they felt distant from their father. In fact, all three participants held a very strong, close bond with their fathers. 
In terms of academic involvement, all three participants indicated that school was of importance to their fathers. In all instances fathers were described as valuing their daughters' learning experiences and were concerned if they thought their daughters did not understand material at school. All of the participants stated that their father would support their learning in various ways such as helping them with homework, asking questions, and taking them to the library. One of the participants indicated that living with her father actually helped her grades to increase and her overall educational experience to become more positive. This supports the research conducted by Lee and Kushner (2008), which indicated that daughters living with single fathers actually fare better on academic achievement than any other group (e.g. sons living with single fathers and sons and daughters living with single mothers).

Aside from academic involvement, participants were asked about their father's involvement in other areas of their lives. In research conducted by Hawkins, Amato and King (2006), it was discovered that single fathers actually have the lowest levels of parental engagement in some domains of involvement such as sports and education. However, this did not hold true for this study as all three participants shared that their father was also involved in extracurricular activities. They attended musical performances, watched their children play sports, and could easily identify their child's group of friends.

Although fathers were involved outside of the home, this study also aimed at understanding how involved they were inside of the home, specifically around housework. Two of the three participants indicated that they had a fairly large amount of responsibility in terms of helping care for the house and this seemingly increased with age. Greif (1985) reported that children in single father families are more likely to participate in housework than children living in two parent families. Further, Greif (1985) suggested in some cases that daughters are used as 
mother substitutes. In general, the female participants in this study seemed to view their involvement in household tasks as more of a personal quest or obvious responsibility. The impression was not given that they felt as though they were mother replacements. For the most part, we found that they took on more chores than perhaps others their age, such as increased babysitting, cooking for the whole family, doing laundry independently, and cleaning bathrooms. This aligns with the work of Weis (2010) who suggests that the maturity of children in single parent families is heightened because of the earlier on-set of family responsibilities.

Risman (1986) found that single fathers typically do not recruit female help from an outsider for housework and household tasks, but rather complete work themselves or in conjunction with children. All of the homes in this study were found to function without the involvement of a female in terms of a cleaning agency or nanny; however, in all cases an aunt provided increased support to the single father family at some point. This support seemed to be most prevalent at the beginning of the new family structure, and less so once the family was more stable and accustomed to their new dynamic.

Risman (1986) reported that, overall, fathers are just as competent in creating strong, intimate relationships with their children as mothers are. The experiences of the three female participants in this study align with this. They each indicated a relationship built upon trust and respect with their father. With time, they all indicated that the relationship grew stronger, and they all continued to rely on their father for love, support, and advice. However, the results from this study vary slightly from Risman's findings (1986) in that the three participants felt the intimacy component was perhaps missing. All three participants noted their own troubles now with communicating emotions and feelings to others and this may be connected to their perceived sense of limited intimacy in their relationships with their fathers. Collectively, the 
participants felt that a mother would have been more in-tune with some important aspects and moments of their teenage years which they did not perceive that their fathers were.

\section{Conclusion}

This exploratory examination of the experiences of three mature daughters of single fathers provides an opportunity to consider what has been an area of limited research in Canada. By delving into the perceptions of these female participants, we have been provided with rich insight into their experiences. At the same time, we recognize that there are several limitations to this study. First, only three female participants were engaged in the study and they represented a fairly significant age spread (eight years). A further study which would incorporate more participants, and from a broader range of ages and socio-economic backgrounds, would certainly add to the fullness of the data. Further, participants had different backgrounds and their family dynamic had shifted for different reasons, such as Emily who lost her mother to illness. Consequently, her experience with her father would have been different than that of the other two who saw their mothers periodically throughout their teenage years. Controlling for some of these factors could provide for a study of the commonalities and differences in their experiences. Finally, the limited research in Canada in the area of single father families limits this study for comparison and theory-building purposes.

We recognize that the focus of this research is very specific: We focus on the perspectives of three daughters of single fathers. We have not made the fathers the centre of the study and we do not examine their perspectives. We do not take into consideration potential differences due to income, ethnicity, religion, sexuality, or age. Our desire was to provide insight into the everyday, lived experiences of daughters of single fathers and, as a result, the focus of 
this study was on three such individuals. We provide this descriptive data as a starting point for further work to be done in examining the experiences of daughters of single fathers.

Each year more and more children reside in single father families, however, a great deal of research still needs to be conducted around this specific family type. Future research needs to consider single fathers' parenting styles, their involvement in their children's lives, the division of household labor, and family roles for both fathers and children. In addition, hearing about the type of influence this family structure has on one's adult identity would help us to better understand children of single fathers and their needs. Further, research to understand how single fathers differ from single mothers would be beneficial and perhaps eliminate the frequent grouping of the two family types. Lastly, more attention needs to be given to the stories of daughters who grow up in these families. By hearing the voices of the daughters of single father families, those who work with them in professional capacities will have a better understanding of their needs. It is inevitable that children and their single fathers will be increasingly present in our community as they interact with institutions and require resources. Thus, it is valuable to society as a whole to increase knowledge and understanding around this group. People from various community organizations and institutions are going to work with such children at some point and will be better prepared to meet their needs and effectively provide support if they understand their overall unique dynamic.

Specifically, it is important for educators to recognize this group of children as having perhaps different experiences at home than others and needing different supports within the classroom. For example, daughters of single fathers may have increased responsibility at home or have different worries and anxieties than other students (money, household tasks that need to be completed, hygiene). Educators need to also be cognizant of things like language used in the 
classroom. For example, teachers should avoid statements like "give this letter to your mom", or "I am going to have to speak to your mom" assuming that every child lives in a home where a mother is present. Further, single fathers may appear to be uninterested in school life because they do not communicate frequently or attend parent-teacher interviews. However, this study indicates that single fathers do in fact care deeply about their child's academic success and overall learning experience.

Teachers and principals, as well as other professionals, have made great strides in supporting children from single parent homes over the past twenty years. It is our view that this awareness needs to be extended to recognize the specific challenges and circumstances that go with being a daughter of a single father. The specific suggestions we have provided are a starting point to supporting these children. As with all students, the most important way that teachers and other professionals can provide support to the daughters of single fathers is by fostering a caring, nurturing classroom context.

In many ways, this study is exploratory. We recognize that by focusing on the experiences of three daughters of single fathers, without considering issues such as ethnicity, religion, or socio-economic status, nor the perspectives of siblings or fathers, that the paper is limited in its scope. However, we see a need for significant Canadian research in this area. Further attention should be given to factors such as the broader familial context, parenting styles, and income. As educators, we would also encourage further study examining the roles of teachers and the impact of school life on the experiences of daughters of single fathers. We welcome further research in this area to consider the experiences and insights of daughters of single fathers. 
Currie \& Sider

The female participants who were involved with this study developed strong relationships with their fathers. These relationships can be characterized with words such as admiration, respect, and love. Fathers were perceived to be deeply committed to their daughters' lives. Although the female participants in this study appeared to have increased responsibility on some level, they did not appear to be resentful of this. Rather, these increased responsibilities were viewed as better preparing them for the world and resulted in an overall greater sense of maturity and independence. Although challenges existed in the single father families, the daughters who participated in this study certainly extolled the merits of working with their fathers as a team. 


\section{References}

Amato, P.R. \& Kane, J.B. (2011). Parents' marital distress, divorce, and remarriage: Links with daughters' early family formation transitions. Journal of Family Issues, 32(8), 10731103.

Biblarz, T.J. \& Stacey, J. (2010). How does the gender of parents matter? Journal of Marriage and Family, 72(1), 3-22.

Bronte-Tinkew, J.B., Scott, M.E., \& Lilja, E. (2010). Single custodial fathers' involvement and parenting: Implications for outcomes in emerging adulthood. Journal of Marriage and Family, 72(5), 1107-1127.

Brown, J.B. \& Lichter, D.T. (2009). Poverty, welfare, and the livelihood strategies of nonmetropolitan single mothers. Rural Sociology, 69(2), 282-301.

Broussard, A. (2010). Research regarding low-income single mothers' mental and physical health: A decade in review. Journal of Poverty, 14(4), 443-451.

Chang, P. \& Deinard, A. (2010). Single-father caretakers: Demographic characteristics and adjustment processes. American Journal of Orthopsychiatry, 52(2), 236-243.

Emmers-Sommer, T.M., Rhea, D., Triplett, L., \& O’Neil. (2003). Accounts of single fatherhood: A qualitative study. Journal of Marriage \& Family Review. 35(1/2).

Fontana, A. \& Frey, J.H. (2000). The interview: From structured questions to negotiated text. In N. Denzin \& Y. Lincoln (Eds.), Handbook of qualitative research $\left(2^{\text {nd }} \mathrm{Ed}\right)(\mathrm{pp} .645-672)$. Thousand Oaks, CA: Sage Publications.

Greif, G. (1985). Children and housework in the single father family. Journal of Family Relations, 34(3), 353-357.

Hawkins, D.N., Amato, P.R., \& King, V. (2006). Parent-adolescent involvement: The relative influence of parent gender and residence. Journal of Marriage and Family, 68, 125-136.

Hellerstein, J.K. \& Morrill, M.S. (2011). Dads and daughters: The changing impact of fathers on women's occupational choices. Journal of Human Resources, 46(2), 333-372.

Isaac, S. \& Michael, W. (1997). Handbook in research and evaluation (3rd Ed.). San Diego: Educational and Industrial Testing Services.

Lee, S.M. \& Kushner, J. (2008). Single-parent families: the role of parent's and child's gender on academic achievement. Journal of Gender and Education, 20(6), 607-621.

Merriam, S.B. (1998). Quantitative research and case study applications in education. San Francisco: Jossey-Bass. 
Risman, B.J. (1986). Can men "mother"? Life as a single father. Journal of Applied Family Studies, 95(102), 95-102.

Stake, R.E. (2000). Case studies. In N. Denzin \& Y. Lincoln (Eds.), Handbook of qualitative research $\left(2^{\text {nd }}\right.$ Ed) (pp. 435-454). Thousand Oaks, CA: Sage Publications.

Stake, R.E. (1995). The art of case study research. Thousand Oaks, CA: Sage Publications.

Statistics Canada. 2006 Census: Family Portrait. Access at: http://www12.statcan.ca/census-recensement/2006/as-sa/97-553/p7-eng.cfm

Supino, L.M. (2002). The experiences and perceptions of children raised primarily by their separated or divorced single fathers: A qualitative study. Dissertation Retrieved from ProQuest Dissertations and Theses.

Wallen, N.E. \& Fraenkel, J.R. (2001). Educational research: A guide to the process (2nd Ed). Mahwah, NJ: Lawrence Erlbaum Associates.

Weiss, R.S. (2010). Growing up a little faster: The experience of growing up in a single-parent household. Journal of Social Issues, 35(4), 97-111.

Wilder, R. (2006, May). It takes a real man to be a good mother; Dad could mix a Gibson with one hand and whip up a mean spaghetti and meatballs with the other: [U.S. Edition Edition]. Newsweek, 147 (21).

Yin, R.K. (2003). Case study research: Design and methods (3rd Ed). Thousand Oaks CA: Sage Publications. 


\section{Appendix:}

Overview of Participants

\begin{tabular}{|c|c|c|c|}
\hline & Emily & Kate & Dana \\
\hline Age at time of study & 23 & 15 & 21 \\
\hline $\begin{array}{l}\text { Languages Spoken } \\
\text { (at home) }\end{array}$ & English & English & English \\
\hline Family Size & $\begin{array}{l}4-\text { Father, older } \\
\text { sister, older brother }\end{array}$ & $\begin{array}{l}3-\text { Father, younger } \\
\text { sister }\end{array}$ & $2-$ Father, no siblings \\
\hline $\begin{array}{l}\text { Highest Level of } \\
\text { Education obtained }\end{array}$ & Secondary School & $\begin{array}{l}\text { Still enrolled in } \\
\text { secondary school, in a } \\
\text { program for gifted } \\
\text { students }\end{array}$ & Grade 11 \\
\hline $\begin{array}{l}\text { Reason for Single } \\
\text { Father Dynamic }\end{array}$ & $\begin{array}{l}\text { Mother passed away } \\
\text { at age } 9\end{array}$ & Parents separated & $\begin{array}{l}\text { Parents were never } \\
\text { married, moved from } \\
\text { a single mother home } \\
\text { in with her father }\end{array}$ \\
\hline $\begin{array}{l}\text { Number of years } \\
\text { living with a single } \\
\text { father }\end{array}$ & Nine & Three & Five \\
\hline
\end{tabular}

